\title{
Philosophical Sketches on Category Theory Applied to Music-Mathematical Polar Semiotics
}

\author{
GABriel PAREyon \\ CENIDIM-INBA, Mexico City, \\ \& CUCSH-UDG, Guadalajara \\ cenidim.gpareyon@inba.edu.mx \\ Orcid: 0000-0002-3471-0102
}

DOI: $10.46926 /$ musmat.2020v4n2.41-51

\begin{abstract}
This is an attempt to combine Matthai philosophy (of Heraclitan inspiration) and Category Theory using the Yoneda Lemma as a means for harmonizing the traditionally opposite values and conceptions dissociated between the Euclidean tradition and Heraclitus thought. The text is divided in three sections: general background and description of Yoneda, a contextualization on Heraclitan aesthetics and polar semiotics (a notion firstly intuited by I. M. Lotman and Th. Sebeok), and an experiment suggested for the revision of the grounds of music theory, with the purpose of conciliate extremely dissociated notions of music (Euclidean vs. Heraclitan) however making part of a common musical experience and knowledge. Conclusions are addressed to hypothesize that Yoneda lemma may support a robust philosophy of music within the field of Category Theory where any group is isomorphic to a subgroup of a permutation, with one-to-one paired correspondences.
\end{abstract}

Keywords: Yoneda embedding. Matthai postulate. Category theory. Polar semiotics.

\section{INTRODUCTION}

$\mathrm{I}$ $\mathrm{n}$ addition to exposing the cohomology between the Yoneda lemma and Matthai postulate ("All thoughts are truthful"), not so much for its demonstration as a logical statement -already satisfied by Grothendieck logic-, a main interest in this article is to discuss major implications of that cohomology over the philosophy of music and describe logical operators for systematic musicology in practice, ${ }^{1}$ particularly in their theoretical expansions of intersemiotic continuum and intersemiotic synecdoche as explained below.

The concept of intersemiotic continuum is formulated in [14, pp. 102-114], and then adapted into a variety of disciplines. ${ }^{2}$ It consists of a succession of symbolic associated systems, transforming

Received: September 29th, 2020

Approved: December 12th, 2020

\footnotetext{
${ }^{1}$ As practice here I assume a main task for musicologists (for analytic, synthetic and heuristic purposes), as well as for music philosophers and composers (creation and transformation of music and musical ideas).

${ }^{2}$ Since February 2011, when On Musical Self-Similarity came out from the imprint in Helsinki, the concept of intersemiotic continuum have had a successful adaptation into the fields of information and communication sciences (L. Isaeva, N. Komina; S. Krestinski, 2012), literature analysis (A. Sousa, 2011; N. M. Dusi, 2014; F. Saggini, 2015), and cognitive science (Iu. Shamayeva, 2016). It comes as a refinement of the concept of semiotic continuum coined by Iu. M. Lotman (1984/1989).
} 
any object however without losing its main features admitted and needed for its ontology or ontological truth. In other words, intersemiotic continuum involves a process that preserves an "informational track" to be transported through a multidimensional space of $n$-meanings (a set isomorphic to $m$-interpretations) in a process known as semiosis. ${ }^{3}$

Perhaps the intersemiotic continuum concept can be easily understood if we suppose, ${ }^{4}$ that a musical pitch interval named $[C, A]$ equals the relative value of $[261.63,440](\mathrm{Hz})$, or the absolute ratio of $[1: 2,3: 5]$ translatable as a rhythmic/metrical pulsation; but also equals the duration interval of [120:100], and also equals the visible light pair of colors [white, yellow], according to Barlow's interpretation. ${ }^{5}$ This strain of continuous translation would intertwine an intrasemiotic system of translation if this occur exclusively within the "musical" domain. But music seems to be a complex set of worlds within worlds; thus, although presumably composing a same "domain", we should think of an intersemiotic continuum even when we do not trespass the cultural field of "music".

Now, the latter presupposition may lead us to a conceptual cul-de-sac, in the jargon of logics known as a Frege chain -in allusion to Gottlob Frege- ${ }^{6}$ with the theoretical cancellation of language and code functioning. However this actually does not happen in natural language, neither in the core of Category Theory as represented by the Yoneda embedding. Therefore, in order to adapt this mathematical concept to musicology, let's firstly recall the Yoneda lemma in its classical form: ${ }^{7}$

$$
X \rightarrow h_{A}=\operatorname{Hom}_{C}(A, X) .
$$

As literally expressed in [12]: for $C$ a locally small category, every object $X$ of $C$ induces a presheaf on $C$ : the representable presheaf $h_{X}$ represented by $X$. This assignment extends to a functor $C \rightarrow\left[C^{o p}\right.$, Set $]$ from $C$ to its category of presheaves. The Yoneda lemma implies $C$ as a full subcategory inside its category of presheaves. The presheaf represented by an object $X$ of $C$ is the functor $h_{X}: C^{o p} \rightarrow$ Set, which sends each object $U$ to $\operatorname{Hom}_{C}(U, X)$ and each morphism $\alpha: U^{\prime} \rightarrow U$ to the function

$$
h_{X} \alpha: \operatorname{Hom}_{C}(U, X)=\operatorname{Hom}_{C}\left(U^{\prime}, X\right),
$$

then, for $f: X \rightarrow Y$ a morphism in $C$, induces a natural transformation $h_{f}: h_{X} \rightarrow h_{Y}$ (for its corresponding graph see [12]), that develops into the commuting diagram in Figure 1.

This is a basic Category Theory description for the Yoneda embedding. Henceforth, let's constrain Matthai postulate "All thoughts are truthful" as a partial feature (logical and philosophical) of Cayley's theorem from group theory, and complementary to Yoneda lemma:

$$
\left\{U^{\prime} \rightarrow U[よ]\right\} \ni\{X \rightarrow Y[\mathfrak{M}]\},
$$

where Yoneda embedding is conventionally formalized $上$, and its Matthai cohomology is formalized $\mathfrak{M}$. This allows us to subsume the latter "philosophical category" under a wider and more complex Set (よ). ${ }^{8}$ Furthermore, if we define $\mathfrak{m}$ as the subset of "musical thoughts", then

$$
\{\mathfrak{M}\} \ni\{\mathfrak{m}\} .
$$

\footnotetext{
${ }^{3}$ See [9].

${ }^{4}$ As [6, p. 97] echoing [4, p. 100].

${ }^{5}$ Barlow's interview at the University of California Television (UCSB, 1 feb. 2008, segment 12:16" to 13:36"): "C was always white [...] F was always green, A was yellow, D was royal red, and for a reason I don't know, A flat was a wonderfully blue colour [...] If you look at the colours of Brahms and Scriabin, they have totally different [colours] to each other, and different to me; words also have colour for me, words and even single letters and single digits have colour".

${ }^{6}$ By association to Frege's paradox, see [14, p. 193].

${ }^{7}$ The Yoneda lemma says that the set of morphisms from a representable presheaf $y(c)$ into an arbitrary presheaf $X$ is in natural bijection with the set $X(c)$ assigned by $X$ to the representing object $c$.

${ }^{8}$ This symbol corresponds to the katakana kana Yo (here for Yoneda) in Japanese phonetic representation.
} 


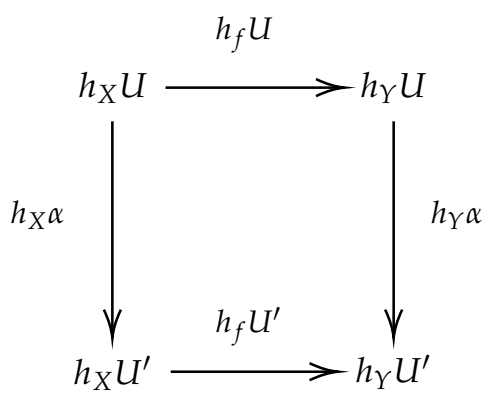

Figure 1: Commuting diagram summarizing the Yoneda lemma.

In consequence, "All [musical] thoughts are truthful". This actually matches very well with Peircean semiotics, as noticed by [17, p. 42]: "truth and communication in Peirce's view are completely isomorphic because the inferential character of argumentation is always dialogic-not between two different people who are in communication but between two different moments of the same mind in which the unity of the semiotic continuum is realized". Here we obviate the concept of musical thought as defined in [2] with especial attention paid to the symmetry principles, and later adapted by [6] to the context of the continuum-discontinuum theory of music.

Now, for the case $\{\mathfrak{M}\} \ni\{\mathfrak{m}\}$, simple membership is trivial. What is useful for musicology is qualitative membership for translatability and systematic coherence among distinct kinds of "objects" $(\alpha, \beta, \ldots)$ and "complexities" $(Y, Z, \ldots)$ in Category Theory, as represented by Figure 2, below.

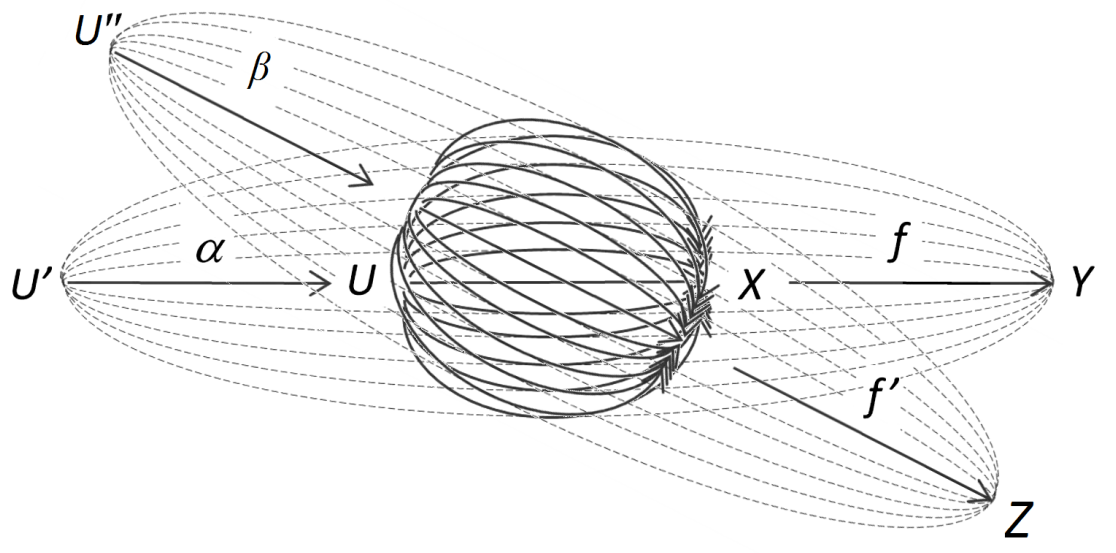

Figure 2: A self-overlapping of the graph borrowed from [12]; A non-trivial adaptation on Yoneda embedding, where a positional variation of the strands polarization suggests the first of $n^{\text {th }}$ correspondences for cohomology, a notion here used for expressing intersemiotic continuum (i.e. parallel universes of signs reciprocally intertwined in degrees of translatable signification).

A subsequent concept is intersemiotic synecdoche, ${ }^{9}$ a powerful tool for the science of signs, which main ability is nothing but jumping from a sign domain to another one, preserving a key component that allows a synecdochic discontinuum (see Figure 3), however consistent and coherent within the network of intersemiotic continuity (with economical virtues in comparison to Figure 2).

\footnotetext{
${ }^{9}$ A notion also introduced in On Musical Self-Similarity. See [14, pp. 101-102, 110-111].
} 


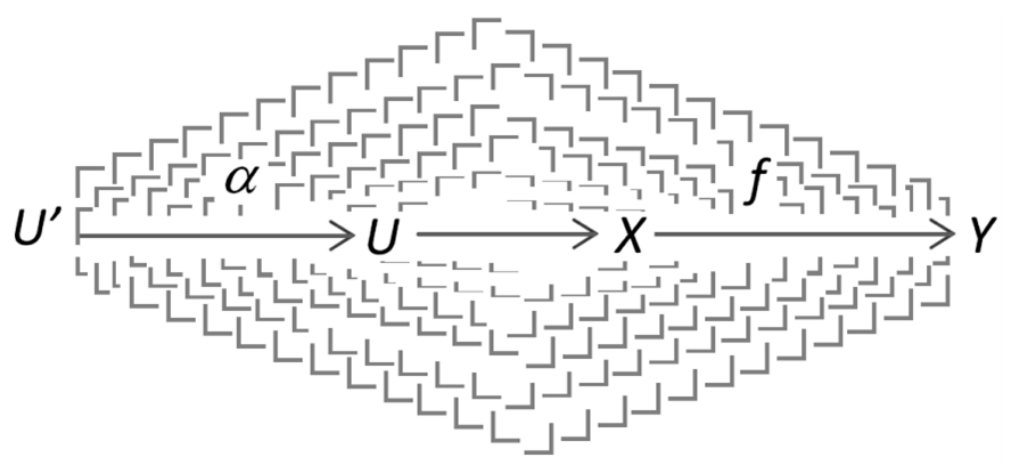

Figure 3: An extension and reinterpretation of the previous scheme, with $\Gamma$ shape segments used to represent non-direct connectivity of intersemiotic (dis)continuity, a segmented lattice that represents a plot of intersemiotic synecdoche. Self-overlapping is also a feature to be $n^{\text {th }}$ polarized-varying.

The figure of "jumping" in this symbolic space is referred to any case where, according to the given example, a pitch interval $[C, A]=[261.63,440]=[1: 2,3: 5]=[120: 100]=[$ white, yellow $]$, and then a different color interval, [purple, green] would correspond to $\left[\Gamma_{\alpha}\right]_{X} \rightarrow\left[\Gamma_{\beta}\right]_{Y} \rightarrow\left[\Gamma_{\gamma}\right]_{Z}$, and so on, without symbolic gaps and where coherency is defined by the properties of a topological space.

\section{A HeRAClitAN POINT OF LISTENING (PHILOSOPHICAL DisCUSSION)}

During the $4^{\text {th }}$ International Congress of Music and Mathematics (UFRJ, October 2019) I offered a couple of lectures,$^{10}$ both philosophically centered on the problem of Western musicology as an axiological tradition. A common topic of both lectures was discussing how this axiology contributed to bias and obscure music theory; especially in musical cultures different to the Western European "classical" one and its derivatives. Then I recalled Heraclitus legacy to suggest that such axiology was not that relevant in Greek pre-Parmenidean times, although Platonism gained the political battle for axiologically depict "good" and "bad" musical ideas and practices, with specific social usages and cultural implications.

How the Yoneda lemma and Heraclitus philosophy are necessarily related, is a component that I could not clarify enough during the meeting; a task to be accomplished here. Let's simplify the case as follows: the Heraclitus motto panta rhei, "everything flows", also known by the metaphor "No man ever steps in the same river twice", has deep semio-epistemic implications. Namely, if the river (or the world) does constantly change and never "is the same" (to itself), then the world is impossible (or at least its communication). This equals Frege's paradox of lack of consistency between object and concept. However, the Yoneda lemma facilitates solving the paradox under the assumption that any object is the coordinative sum of all its necessary definitions and even of all its truthful definitions.

The "problem" with the latter is, then, that no any dictionary or grammar could hope to rule natural language. But languages, as indeed also happens with music, are much more complex than the highest complexity of functionalizing lexicons and syntax. Usefully, what Yoneda lemma teaches us on this, is rather that such a "problem" does not exist; and our mechanical-analytic

\footnotetext{
10"Non-Linear Approach to Popular Musicalities through a Non-Western Mathematical Understanding of Rhythm, Intonation and Locally-Generated Harmony" (Oct. 23 $\left.3^{\text {th }}, 2019\right)$ \& "Peircean Mathematics for Musicology: Transcending Heraclitus Melancholy through Harmonic Synechism" (Oct. $\left.25^{\text {th }}, 2019\right)$.
} 
focus on languages was either adequate to deal with semiotics of music from that starting point.

Under this clarification, we may assess the relationship of an object and its conceptualization, as the self-construction of conceptual clouds (i.e. cumuli of concepts) that actually allows us to identify the object; even when the manifold construction of these clouds may partially fall into local and apparent contradiction (e.g. the object as a "cloud of meanings" and simultaneously as concrete specificity). These contradictions, logically harmless ones, may even be described as extremely far allocated from each other, however making part of a same wholeness of sense. Then the notion of polar semiotics enters the scene, connecting Category theory to musical semiotics.

In this context, I employ the conceptual "polarization" between Euclidean principles and the Heraclitan philosophy with the aim of unveiling a hidden continuum between these foci, presumably opposite as models of thought and imagination. A good start would be the point itself as undefined or blurry defined by the Heraclitan model. Then I pose the question whether this human comprehension of the world, could rather be biased by our own way to build our models of comprehension (a conceptual hesitation that actually modern physics do reflect in its manner, along the discussion of particle and/or wave as a correct characterization for dynamical systems/objects behavior). This blurry opposition between contraries and somehow complementary semiotics are studied below under the proposed label of polar semiotics. ${ }^{11}$

Contrary to what is established by the Euclidean Elements, Heraclitus did not emphasize a definition of point and straight line, as key concepts before any arithmetic, geometrical or algebraic development. In contrast, Heraclitus conceives an absolute impermanence for any state of mind or matter, as the crucial knowledge for philosophy and mathematical truth-a non-Euclidean one. This conceptualization, less intuitive than the stability of the point extended as a pure line, straight or curve, was condemned by a cultural system that needed to satisfy certainty in order to preclude ambiguity and to banish any doubt on the aesthetic, religious and political establishment of the Greek republics.

The fundamental concept of the point as "that which has no part" is analogous to the Democritan atom as "that which has no partition", and these is closely related to the logical definition of unity and nothingness, which, in their turn, are the fundamental "bricks" for the building of Euclidean space and commensurability. Thus, in one hand, we gain a logically deterministic axiomatics, and an absolutist notion of mathematical truth and certainty. But, on the other hand, we lose a charming intuition of complexity, irregularity, uncertainty and impermanence, fundamental to assess our notions of probability. We gained a perfect geometry Platonic paradise in our minds, but we lose focus for understanding what happens in our bodies and ecologies.

When Roman politicians understood the net weight of this conceptual unity, Constantine The Great adopted monotheism and created the most powerful empire of the globe, weaving a religious, military and political network which had a decisive impact in what we now name as Western culture. Then the concepts of purity of the regular polygons and Platonic solids became politically useful, and the indivisible point, the pure line, straight or curve, the circle and noticeably the sphere, became symbols for political and religious usage, to the extent that the Christian church, monopolized by Rome, identified the sphere, the circle and the point, with the absolute image of God.

Thinkers like Giordano Bruno and scientists like Galileo suffered serious threats for questioning the supposed purity of the Euclidean-Aristotelian geometry, and for doubting the geocentric model attributed to Ptolemy. The philosophical arguments for this symbolic association between moral, politics, aesthetics and music, were already formulated by Plato, definitely refusing the conception of Heraclitus, of a cosmos based on change and constant deviation under the concept of clinamen

\footnotetext{
${ }^{11}$ Although not yet formalized, the notion of polar semiotics is already traceable in [19, p. 29]: "In the web of nature, plants are, above all, producers [...] The polar opposites of plants are the funghi, nature's decomposers".
} 
("the part that is partition itself").

The scholastic tradition of Platonic-Aristotelian influence, cursed Heraclitus ideas and he passed to be mockingly described as The Obscure or The Weeping Philosopher. Even to this day a Roman characterization of Heraclitus portrays him as-quoting Sotion of Alexandria-"overtaken by tears, [and] Democritus by laughter". Throughout the Middle Ages, Heraclitus ideas were also ridiculed, supposedly for being related to the Epicurean tradition that look for an equilibrium between pleasure and moderation.

Now, my purpose on revising this story on Greek and Roman philosophy, must be directed to the question of what happens if we remove Heraclitus' anathema, attempting to assess his philosophy from the understanding of modern Non-Euclidean mathematics, and which consequences would have this regarding music.

First of all, we have to confront Heraclitus most known argument on impermanence, towards the thought of Parmenides, his contemporary. Heraclitus is supposed to say that "No man ever steps in the same river twice". Parmenides answers with a fully deterministic logical sentence: "Whatever is, is, and what is not cannot be". However we notice, from a logical rigorous perspective, that this Parmenidean answer has no falsifiability. In fact, it works as a tautology and redundant self-consistency, not because of a lack of axiomatic truth, but because of triviality.

A similar judgment can be applied confronting Heraclitus' clinamen to the Euclidean tautological depiction of the point as "that which has no part", also related to the Platonic-Aristotelian conception of purity as a necessary characteristic of the point, the circle and the sphere. Perhaps the consequences of defending Heraclitus conceptions on the impermanency of a non-Euclidean point, line, atom and space would change our understanding on the sense and intuition of space, distance, shape and time.

A necessary step back in this way, would be revising the ancient Greek concept of "chaos", because of the relevance of this notion in Pre-Socratic mathematics. A glimpse into the most studied ancient sources, allows us to identify the concept of chaos in an Epicurean interpretation, as "the first state of the universe", and in Lucretius as the "unformed matter". No surprise. In contrast, the Pythagorean interpretation of chaos as "the name for [number] one" is striking. This last conceptualization leads us to think on Heraclitus impermanence of the unity. Indeed, this thesis was defended by the Epicureans, and by the followers of Lucretius' De rerum natura, a famous epicurean treatise on existentialism, ethics and aesthetics.

Up to this point of history, or rather up to this history of the point, there is no mathematical proof for any of Heraclitus postulates on spatial and numerical impermanence. If so, a proof may come from recent times, although through an unexpected way, after the computational discovery of deterministic chaotic behavior from simple non-linear dynamical equations, such as the logistic map: a polynomial mapping which chaos strongly depends on the initial conditions for the function iteration, originally designed by Robert May (1936-2020) with the purpose of modeling demographic growing (a property also observable, of course, within many other chaotic non-linear mappings). Next, third and closing section, is yet far to systematize this feature for musical definitions. Nevertheless, the actual discussion is whether this kind of polar semiotics may lead musicology to its own finding for a possible systematization on this route.

\section{Polar Semiotics: Edges of Parallel that Meet at Infinity}

Whether an aphorism can logically be synthesized as an axiom and further sprout into a morphism (a structure-preserving map from one abstraction to another analogous one), the intersemiotic continuum described at the first section of this text proposes the Yoneda embedding for connecting any categorical subtleties to this morphism (see Figure 4). 
The following experimental, enunciative exercise consists of a search for a common lineage bonding music theory and mathematics (or poetry and philosophy), where [よ] does represent a Yoneda subset (a segment of the Yoneda embedding), both as a musical definition and an abstract proposition, "polarized" between the Euclidean tradition (here symbolized $\mathfrak{M}_{a}$ ) and its Heraclitan "complement" ( $\mathfrak{M}_{b}$, where the letter $\mathfrak{M}$ stands for Matthai logic based on the postulate "All thoughts are truthful"). The symbol o denotes information-thermodynamic equilibrium (cf. $[22,20,5])$. Following examples are provided on purpose from sources that somehow make evident their membership to a semiotic polarization, nevertheless comprised by a Yoneda embedding (formally represented by symbol $\downarrow$ ) to be built as a morphism.

Infinity of poles may constitute the fuzzy edges of intersemiosis composing a simple object embedded in a Yoneda complex. The following examples are just few cases of simplification, useful for music theory revision and its possible transformation within this context. In the left column a postulate is posed, following the Euclidean tradition both in formal and imaginary qualities. The right column, instead, shows postulates rather empathetic to Heraclitus attributed thought.

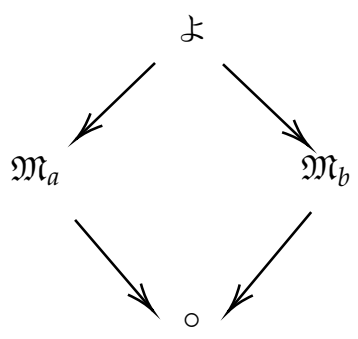

Figure 4: Flux map for the diagram below (following pages): a morphism model for a Yoneda cycle representing equilibrium between to semiotic "poles" $\left(\mathfrak{M}_{a} \leftrightarrow \mathfrak{M}_{b}\right.$ ). Symbol $ょ$ (katakana kana Yo) stands for Yoneda; symbol $\mathfrak{M}$ for Matthai election (i.e. at least a partial, yet context-coherent validation of his postulate), and symbol o for information-thermodynamic equilibrium between the semiotic poles (left - right).

\section{Point}

$\left[L_{1}\right]$

Euclidean $1\left[\mathfrak{M}_{a}\right]$

"The geometric point is an invisible thing. Therefore, it must be defined as an incorporeal thing. Considered in terms of substance, it equals zero."
Heraclitan $1\left[\mathfrak{M}_{b}\right]$

"In a basic two-dimension carbon structure, straight lines may represent precondition for the Euclidean straight line intuition, and their vertices represent precondition for the Euclidean point." 


\begin{abstract}
Line
[よ2]
\end{abstract}

Euclidean $1\left[\mathfrak{M}_{a}\right]$

"The geometric line is an invisible thing. It is the track made by the moving point; that is, its product. It is created by movementspecifically through the destruction of the intense self-contained repose of the point."

[8, p. 51]

Heraclitan $1\left[\mathfrak{M}_{b}\right]$

"The border zone is the reality, and the dividing line, the abstraction of it [...] [by its polarization] is the membrane that separates two media of different density"

F. Ratzel (apud [10, p. 182])

\section{Rhythm}

$$
\text { [ } \left.\text { L }_{3}\right]
$$

Euclidean $1\left[\mathfrak{M}_{a}\right]$

"Repetition is a potent means of heightening the inner vibration and is, at the same time, a source of elementary rhythm which, in turn, is a means to the attainment of elementary harmony in every form of art."

[8, p. 19]
Heraclitan $1\left[\mathfrak{M}_{b}\right]$

"There is no space and time, but spacetimes in which natural phenomena and human events sink, impregnating themselves with the qualities of each place and each moment."

[21, p. 174-175]

(also quoted in [10, p. 333])

\section{Sound \\ $\left[よ_{4}\right]$}

Euclidean $1\left[\mathfrak{M}_{a}\right]$

[The symbol has an] "inner sound [...] The point belongs to the more confined circle of habitual everyday phenomena with its traditional sound, which is mute".

[8, p. 19]

\section{Heraclitan $1\left[\mathfrak{M}_{b}\right]$}

"We study the ear to know the nature of sound and the nose to know the nature of odors. When Heraclitus said that he searched for himself, he knew that to know the cosmos he must know himself because he was an exact microcosm of that cosmos."

\section{Melody}

[よ5]

Euclidean $1\left[\mathfrak{M}_{a}\right]$

"Succession of sounds somehow ordered according to the laws of rhythm and modulation, that it forms a pleasant sense to the ear".
Heraclitan $1\left[\mathfrak{M}_{b}\right]$

"Think that everything sings [...] bathe your melancholy in the rhyme of the falling water, and you will understand many things that are hidden from you today and then you will know this: that music is the soul of the Universe" 
Euclidean $1\left[\mathfrak{M}_{a}\right]$

"[Let's an] inventory:

Elements: two points + plane.

Result:

1. the inner sound of a point,

2. repetition of the sound,

3. double sound of the first point,

4. double sound of the second point,

5 . sound of the sum of all these sounds".

[8, p. 32]

\section{Duration}

$\left[よ_{7}\right]$

Euclidean $8\left[\mathfrak{M}_{a}\right]$

"The notion of interval of duration would be the product of a measurement carried out between two points located on different moments of the temporal evolution of our [spatiotemporal] macrospectrum."

[6, p. 133]

\section{Composition}

Euclidean $1\left[\mathfrak{M}_{a}\right]$

"A composition is nothing other than an exact law-abiding organization of the vital forces which, in the form of tensions, are shut up within the [spatio-temporal] elements"

\section{Heraclitan $1\left[\mathfrak{M}_{b}\right]$}

"These two poles are so far apart from each other that between them there is room for a whole world of sensations of infinite beauty [...] When trees resemble waterfalls of color! [...] It also fits between one pole of beauty and another."

\section{[28]}

\section{Heraclitan $1\left[\mathfrak{M}_{b}\right]$}

"What, in fact, is the compositional field? Should it be characterized as a theoretical field, a field of practices, a field of studies, of learning, of creations, of all this together? How is it internally articulated? Is there a discernible outline-definition, borders, intersections, internal segmentations (parts), gradations of difficulty, lines of connection between what is elementary and what is advanced? Can it be thought of as a static set, or necessarily as a process? What kind of process?"

$[8$, p. 86]
$\stackrel{\circ}{\downarrow} \underset{13, \text { p. 9] }}{\downarrow}$
$n^{\text {th }}$ intersemiotic $\left[\mathfrak{M}_{a} \leftrightarrow \mathfrak{M}_{b}\right]$ continuity
(Euclidean - Heraclitan dissipative self-transformation).




\section{CONClusion}

In a recent past the academy and its formalized knowledge disapproved any interpretation of musical concepts that did not adhere to the orthodoxy modeled by the rational principles celebrated by Enlightenment and Positivism. Now we see that notions so apparently contradictory or dissociated from each other can actually be part of a rich totality, benefiting our manifold understanding of music.

The presented conceptualization for polar semiotics may contribute to studying music as the body/mind-individual/social thermodynamic equilibrium that Ilya Prigogine (1917-2003) used to identify as dissipative structures; in this particular case, epistemes (at least musical ones) whose intertwined relationships can be observed through the Yoneda method.

The more important a concept does appear in the human mind and in social history, the more heterogeneousness of thoughts around it. This, which is a "problem" for classical philosophy, ${ }^{12}$ is the greatest virtue for the concepts of philosophy behind polar semiotics. Yoneda lemma facilitates this recognition for philosophy in general, and for musicology in particular.

For the provided examples in the third section of this essay, I could not omit the historical skilfulness of Kandinsky to transform the Euclidean postulates and to synthesize human feelings and reasoning translatable into a helpful intermediation that allows us to communicate among our mind polarizations. May this help to a common desired harmonization of our critical moment as a self-questioning society.

\section{REFERENCES}

[1] Carrillo, J. (1954) Teoría lógica de la música. Mexico City: Manuel Casas Impresor.

[2] Chávez, C. (1961) Musical Thought (Charles Eliot Norton Lectures). Cambridge: Harvard University Press.

[3] Lima, P. (2012) Teoria e prática do compor: Diálogos de invenção e ensino. Salvador: EDUFBA.

[4] Cowell, H. (1964) New Musical Resources. New York: Something Else Press.

[5] Eco, U. (2016) La struttura assente: La ricerca semiotica e il metodo strutturale. Milano: La nave di Teseo.

[6] Estrada, J. (1994) Théorie de la composition: discontinuum - continuum. Thesis (Ph.D. in Music), Université de Strasbourg II.

[7] Geldard, R. (2000) Remembering Heraclitus. Herndon: Lindisfarne Books.

[8] Kandinsky, W. (1926) Punkt und Linie zu Fläche. Beitrag zur Analyse der malerischen Elemente. München: Verlag Albert Langen.

[9] Lotman, I. (1989) The Semiosphere, Soviet Psychology, 27, pp. 40-61.

[10] Matthai, H. [Q.] (2002) Textos filosóficos (1989-1999). Mexicali: Universidad Autónoma de Baja California.

[11] Matthai, H. [Q.] (2012) Todos los pensamientos son verdaderos ("All thoughts are truthful"). Ciudad de México: Verdehalago.

\footnotetext{
${ }^{12} \mathrm{~A}$ "problem" in the context of Western civilization, due to the obstacles that it supposes for an exclusive and unitary definition.
} 
[12] nLab (2020) Yoneda embedding in nLab, https://ncatlab.org/nlab/show/Yoneda+embedding.

[13] Nervo, A. (1898) Llueve. El ritmo del agua. El ritmo universal. Obras completas. Madrid: Aguilar, 1952 (I: 798—802).

[14] Pareyon, G. (2011). On Musical Self-Similarity, Helsinki: Acta Semiotica Fennnica.

[15] Pareyon, G. (2016) Patterns of Materiality/Immateriality: Dialectics in Epistemology under the New Scientific Paradigm. In: Reyes-Harcia, E.; Châtel-Innocenti, P.; Zreik, K. (eds.). Archiving and Questioning Immateriality. Paris: Europia, pp. 57-70.

[16] Pareyon, G. (2017) Tuning Systems Nested within the Arnold Tongues: Musicological and Structural Interpretations. In: Pareyon, G.; Pina-Romero, S.; Lluis-Puebla, E.; Agustín-Aquino, O. (eds.). The Musical-Mathematical Mind: Patterns and Transformations. Berlin: Springer, pp. 221-230.

[17] Parmentier, R. (1985) Signs' Place in Medias Res: Peirce's Concept of Semiotic Mediation. In: Mertz, E.; Parmentier, R. (eds.). Semiotic Mediation: Sociocultural and Psychological Perspectives. Orlando: Academic Press, pp. 23-47.

[18] Rousseau, J.-J.; Dauphin, C. (2008) Le dictionnaire de musique [1767] de Jean-Jacques Rousseau: une édition critique, Bern: Peter Lang - Varia Musicologica.

[19] Sebeok, T. (2001) The Study of Signs. In: Sebeok, T. Signs: An Introduction to Semiotics.Toronto: University of Toronto Press, pp. 25-38.

[20] Shannon, C.; Weaver, W. (1949) The Mathematical Theory of Communication. Urbana: University of Illinois Press.

[21] Soustelle, J. (1982) El universo de los aztecas, Mexico City: FCE.

[22] Wiener, N. (1948) Cybernetics: Or the Control and Communication in the Animal and the Machine. Cambridge: The MIT Press. 